\title{
Elementos para uma caracterização da população utente do Centro de Estudos da Profilaxia da Droga/Norte
}

\author{
MANUELA FLEMING \\ JOLIO MACHADO VAZ*
}

\section{INTRODUÇÃO}

Pretende-se fundamentalmente com este trabalho dar um contributo ao conhecimento do «fenómeno drogas através do estudo da populaçăo, na sua quase totalidade adolescentes e jovens, que têm solicitado os serviços de tratamento do Centro de Estudos da Profilaxia da Droga (C.E.P.D.) - Norte.

Os resultados referem-se portanto a uma categoria especifica de consumidores, aqueles que num determinado momento da sua experiência de consumo, e por motivaçóes diversas, nos trazem o apelo: «Quero parar, ajude-me!»

Os resultados não poderão portanto, como é óbvio, ser extrapolados, sem reservas, para a massa anónima de consumidores de drogas. No entanto, parece-nos que a nossa amostragem, embora pequena, é significativa e permite situar com mais objectividade e rigor quem săo, o que fazem, o que usam os consumidores da droga.

Como psicoterapeutas interessou-nos, antes de qualquer outra abordagem, ter uma visão o mais concisa possível da situaçáo social dos

- M. F. 6 Psicóloga no Centro de Estudos da Profilaxia da Droga, J. M. V. 6 Assistente de Psicologia Básica no I.C.B.A.S. é Técnico no C.F.P.D./Norte. Comunicaçlo apresentada no I Congresso de Psiquiatria da Adolescência, realizado na Figueira da Foz, $\mathrm{em}$ Novembro de 1979. jovens com quem contactamos quotidianamente, procurando respostas, que dada a complexidade da problemática droga, nem sempre podem ser encontradas apenas por via médica ou psicoI6gica, mas conjugando estas com intervenções de âmbito social.

Esperamos que este trabalho possa abrir novas pistas de investigação e contribuir para a planificação de estratégias de prevenção primária ao nível da adolescência.

\section{CARACTERIZAÇÃO DA POPULAÇÃO UTENTE}

A população estudada compreende 191 indivíduos, que consultaram o nosso Centro desde a sua abertura, em Novembro de 1977, até De. zembro de 1978. Todos de nacionalidade portuguesa à excepçấo de uma rapariga francesa.

Vêm ao Centro normalmente sozinhos e. quando acompanhados, são-no o mais frequentemente pela mãe ou amigos.

A chegada até ao Centro faz-se através de percursos variados, mas na maioria dos casos (58\%) vêm ter connosco depois de encaminhados por outras instituições ou depois de aconselhados por familiares; em $30 \%$ dos casos vêm por iniciativa própria. Cabe dizer que a nossa consulta preserva 0 anonimato, 6 gratuita e voluntária. 


\subsection{Sexo e idade}

Desses 191 indivíduos, 163 (ou seja: 85,3\%) são do sexo masculino, e apenas 28 (ou seja: $14,6 \%$ ), são do sexo feminino.

Quanto à idade, constata-se que a maior percentagem de indivíduos se situa, entre os grupos etários que considerámos, no grupo dos 15 aos 19 anos.

$87,6 \%$ dos indivíduos que nos consultam têm idade compreendida entre os 15 e os 24 anos. No país (fonte: Anuário Estatístico) em 1977, o mesmo grupo etário representava apenas $16,8 \%$ da população total; esta comparação comprova claramente que se trata de um fenómeno que abrange fundamentalmente a adolescência e juventude.

Um apuramento mais afinado permite-nos constatar que as percentagens mais elevadas se
QUADRO I

REPARTIÇÃO DOS INDIVÍDUOS SEGUNDO O SEXO E A IDADE (EM \%)

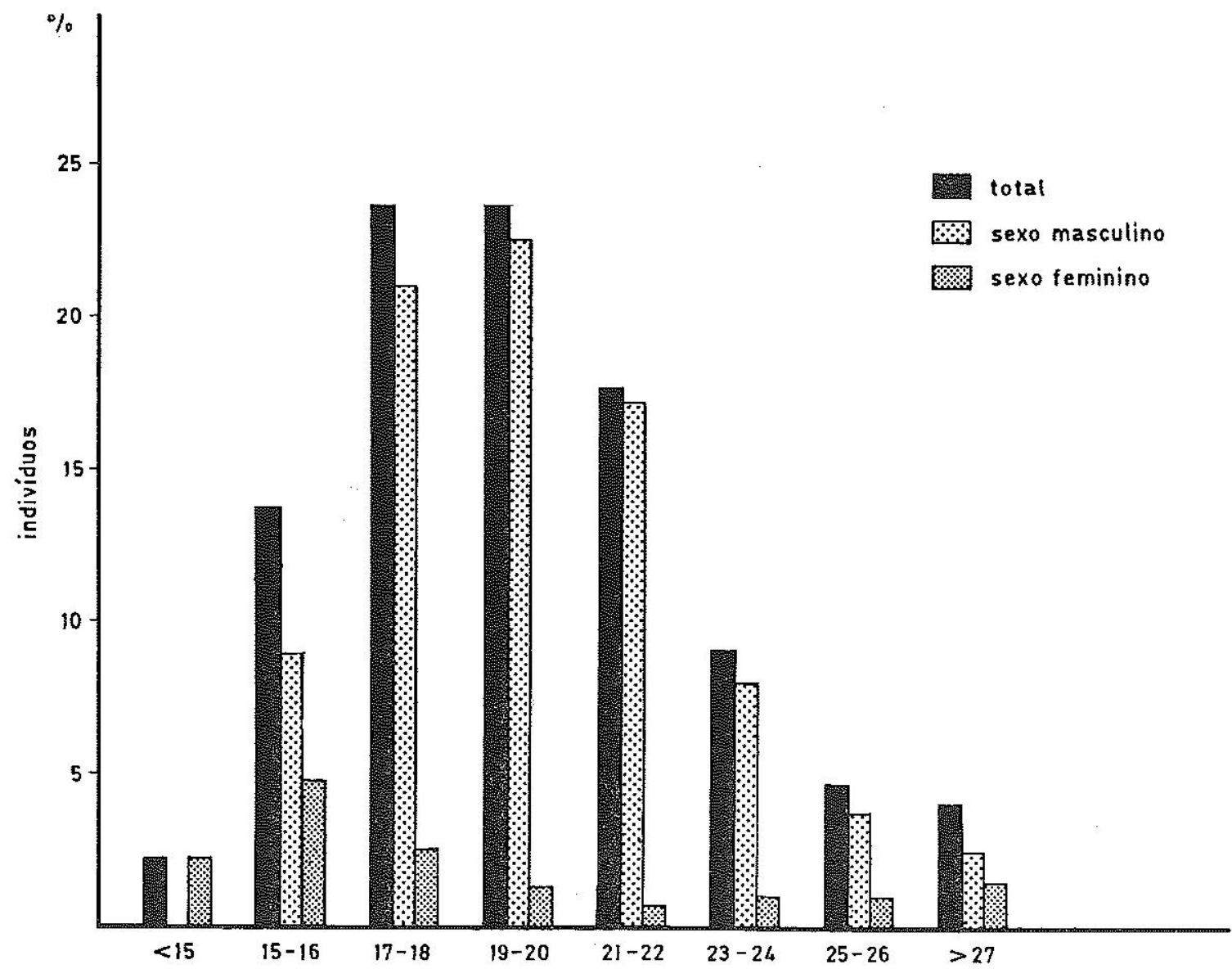

Fig. 1

$\begin{array}{lrrrr}\text { Menos de } 15 & - & 2,1 & 2,1 & \\ 15 \text { a } 19 & 37,7 & 7,9 & 45,6 & 8,7 \\ 20 \text { a } 24 & 40,0 & 1,6 & 42,0 & 8,1 \\ 25 \text { a } 29 & 5,2 & 1,0 & 6,2 & 7,0 \\ \text { Mais de } 30 & 1,0 & 1,6 & 2,6 & \\ \text { Sem resposta } & 1,0 & 0,5 & 1,5 & \\ \text { TOTAL } & 85,3 & 14,7 & 100,0 & \end{array}$

*: Fonte: Anuário Estatístico de 1977 
situam para os rapazes no grupo etário dos 17 aos 20 anos e para as raparigas dos 15 aos 16 . Estas iniciarão portanto o consumo de drogas mais cedo do que os rapazes.

Temos portanto uma população utente, em grande maioria (90\%) com menos de 25 anos, com uma idade média de 20,4 anos, em que, no total, os homens são cerca de 6 vezes mais numerosos do que as mulheres.

Esta predominância dos homens é um facto constatado também em numerosos outros trabalhos. Assim, por exemplo, no estudo feito por Fréjaville e colaboradores, referido no livro Les jeunes et la drogue, para França, em 1972, a proporção encontrada é de 3 homens para 1 mulher.

Curiosamente, o trabalho de Dias Cordeiro e Nuno Miguel «Os toxicómanos na região de Lisboa» encontra, para consulta do Hospital
Santa Maria, em 1977, uma quase paridade entre os dois sexos.

\subsection{Situação social}

\subsubsection{Estado civil e local de residência}

Quanto ao estado civil, constata-se que a grande maioria $(88 \%)$ são solteiros, vivendo na maior parte dos casos com os pais ou membros da família.

$O$ estudo do local de residência permite-nos constatar a seguinte distribuição por distritos e concelhos: cabendo as maiores percentagens aos concelhos do Porto e Vila Nova de Gaia, de onde provém a maioria $(66,3 \%)$ dos nossos utentes.

Verifica-se também, pelos dados obtidos, que a nossa população provém essencialmente dos meios urbanos.

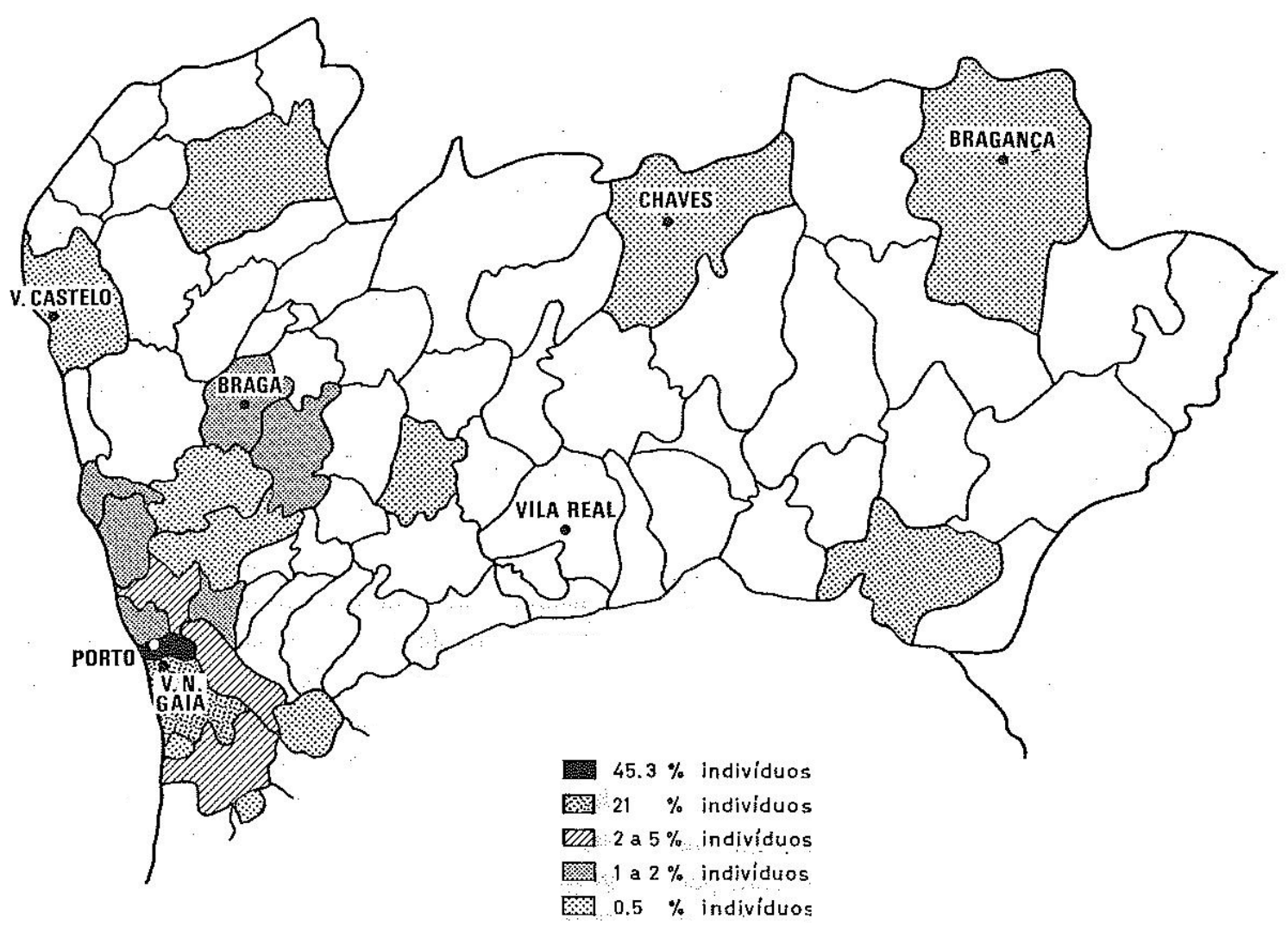

Fig. 2-Origens residenciais dos utentes do CEPD/Norte 


\subsubsection{Nivel de formação escolar}

A análise do nível de formação escolar atingido pelos nossos utentes permitiu-nos verificar que os estudos efectuados se repartem da seguinte forma:

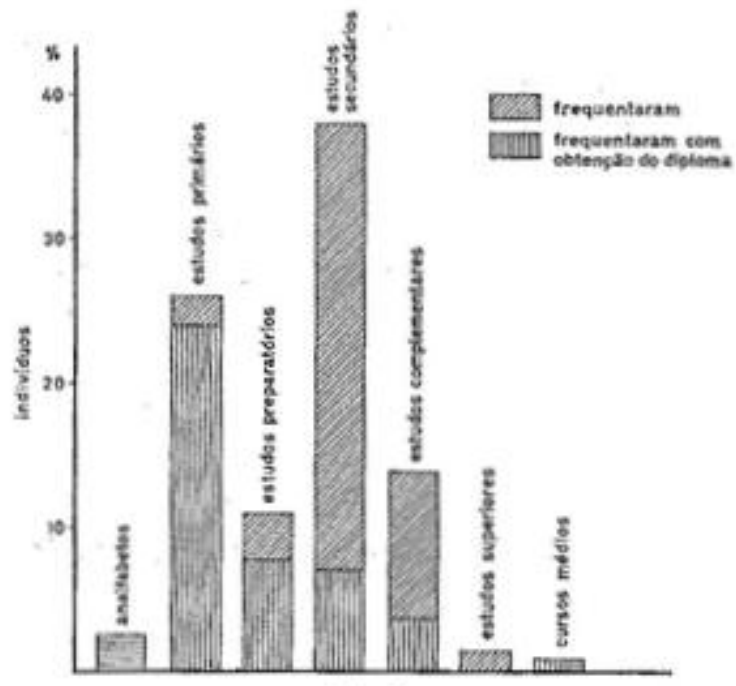

Fig. 3

A maior percentagem é pois de indivíduos que chegaram ao secundário, embora apenas uma pequena percentagem tenha conseguido completar.

Em termos de diplomas obtidos, a maioria relativa corresponde a individuos com o $2 .^{\circ}$ ano do liceu ou equivalente.

\section{QUADRO II}

REPARTICĀO DA POPULACX̃O TOTAL SEGUNDO AS HABILITACOES ESCOLARES POSSUIDAS (EM \%)

Diploma da 4." classe

27,3

Diploma do 2." ano

31,4

Diploma do 5." ano

Diploma do 7." ano

Diploma curso medio

Sem diplomas

24,6

5,2

1,0

Sem resposta

4,2

6,3

O estudo da populaçäo estudante, que representa $17,3 \%$ da nossa população total, permite-nos constatar que, destes, a maioria vem do ensino secundário e complementar.
QUADRO III

REPARTICÃO DA POPULACX̃O ESTUDANTE SEGUNDO O TIPO DE ENSINO FREQUENTADO (EM \%)

\begin{tabular}{lr} 
Ensino preparatório & 9,1 \\
Ensino secundírio & 45,5 \\
Ensino complementar & 30,3 \\
Propedeutico & 3,0 \\
Ensino superior & 6,1 \\
Sem resposta & 6,0 \\
\hline
\end{tabular}

Se compararmos a idade normal que corresponde ao nível escolar, constata-se que a nossa população estudante apresenta $\mathrm{em}$ grande maioria idades superiores àquelas que seria normal encontrar para os níveis de escolaridade referidos, o que nos faz pensar que associados aos problemas da droga andarão dificuldades de ordem escolar ou vice-versa.

A idade média dos estudantes, que é de 17,4 anos, é inferior à idade média da população total (20,4 anos). Para aquele valor contribui particularmente a baixa média de idade das raparigas estudantes, que é de 15,3 anos.

Verifica-se também que entre a população estudante a distribuiçăo por sexos é menos acentuada. $O$ peso relativo das raparigas 6 aqui ligeiramente superior, ou seja, $18 \%$ são do sexo feminino e $82 \%$ do sexo masculino, o que deixa supor que os factores culturais e ambientais estarão mais esbatidos no meio estudantil.

\subsubsection{Estatuto social}

Passemos agora à análise do estatuto social.

A repartição em percentagem permite-nos constatar que estamos perante uma populaçăo em que mais de $50 \%$ são inactivos, entendendo por esta categoria os desempregados e os que nunca tiveram ou não têm ocupação.

Verificamos também uma diferença ao nível da repartição por estatuto social, entre a população masculina e feminina. Esta distribui-se principalmente por entre estudantes e inactivos, enquanto a masculina entre inactivos e trabalhadores. 
QUADRO IV

REPARTIC̄̃̃ DA POPULAC̄ÃO TOTAL SEGUNDO O SEXO E O ESTATUTO SOCIAL (EM \%)

Estudantes

Exercendo profissão

Inactivos

Sem resposta

Feminino

Estudantes

Exercendo profissão

Inactivos

Sem resposta

Masculino

Estudantes

Exercendo profissão

Inactivos

Sem resposta

A análise da repartição do estatuto social por grupos de idade, permite-nos constatar que para qualquer grupo de idade a percentagem mais elevada continua a caber aos inactivos, e que estas percentagens são particularmente elevadas para os indivíduos de mais de 21 anos.

\section{QUADRO V}

REPARTICÃO DA POPULAC̃̃O TOTAL SEGUNDO O ESTATUTO SOCIAL E O GRUPO ETÁRIO (EM \%)

\begin{tabular}{lrrrr}
\hline & Estudantes & $\begin{array}{r}\text { Exercendo } \\
\text { profissäo }\end{array}$ & Inactivos & TOTAL \\
\hline Menos de 17 & 37,9 & 13,8 & 48,3 & 100,0 \\
17 a 20 & 23,3 & 36,0 & 40,7 & 100,0 \\
21 a 24 & 3,8 & 25,0 & 71,2 & 100,0 \\
Mais de 25 & & 41,2 & 58,8 & 100,0 \\
\hline
\end{tabular}

Pensamos que este é um dos resultados que gostaríamos de comparar com outros relativos a estudos mais representativos. Provavelmente não iríamos encontrar as mesmas percentagens, até porque a população que nos procura é de certo modo uma população em que um agravamento progressivo dos problemas, quer de ordem individual quer social, os levou a chegar até nós e que a situação de desemprego para isso terá certamente contribuído.
QUADRO VI

REPAR'TIÇÃO DA POPULAÇÃO ACTIVA (EM \%)

Por sector de actividade

Primário

$5 ; 2$

Secundário

44,8

Terciário

50,0

Por estatuto sócio-profissional

Assalariados produtivos

39,6

Assalariados não produtivos

60,4

Por outro lado, o estudo dos dados fornecidos por aqueles que declararam exercer ou ter exercido uma profissão (96 casos) permite-nos verificar que se empregam predominantemente em actividades ligadas ao sector terciário (na maior parte dos casos empregados de comércio e de escritório), en menor grau ao sector secundário (operários) e apenas em muito pequena percentagem a actividades ligadas à lavoura ou pescas.

Se tivermos em conta que a percentagem da população activa que no nosso país se emprega no sector terciário é de 34,3\% (fonte: Anuário Estatístico de 1977), verificamos que a percentagem encontrada na nossa amostra é bastante superior $(50 \%)$, o que ao nível do estatuto sócio-profissional vai determinar uma população que na sua totalidade é assalariada. Dentro dos assalariados, quase $2 / 3$ são trabalhadores de serviços, enquanto os restantes são operários.

Se referirmos agora estes números, não só em relação à população activa mas em relação à população total (191 casos), verificamos que o peso dos operários é de $20 \%$ e o dos assalariados não produtivos é de $30 \%$.

\section{QUADRO VII}

REPARTIÇÃO DA POPULAÇÃO TOTAL POR ESTATUTO SÓCIO-PROFISSIONAL (EM \%)

$\begin{array}{ll}\text { Estudantes } & 17\end{array}$

Operários $\quad 20$

Assalariados não produtivos 30

Sem ocupação $\quad 22$

Situaçón mal definidas e sem resposta $\quad 11$ 
Constatamos também que, para uma grande parte, as profissōes exercidas estão aquém do nível de formação atingido.

\subsection{Situação militar}

Passemos agora à análise de algumas variáveis relacionadas com a situaçũo familiar da nossa população. Para cada variável indicaremos o número de casos estudados, pois que năo foi possível obter estes dados para os 191 casos anteriormente estudados.

\subsubsection{Situaçāo matrimonial dos pais}

Quanto à situaçãa matrimonial dos pais das 131 respostas que foi possível obter podemos verificar que uma grande percentagem $(31,3 \%)$ é de famílias em que o pai ou a mãe ou ambos estăo ausentes, o que, dadas as características do nosso país, e embora com algumas reservas, nos permite fazer pensar que o divórcio ou a ausência de um dos pais são factores de risco.

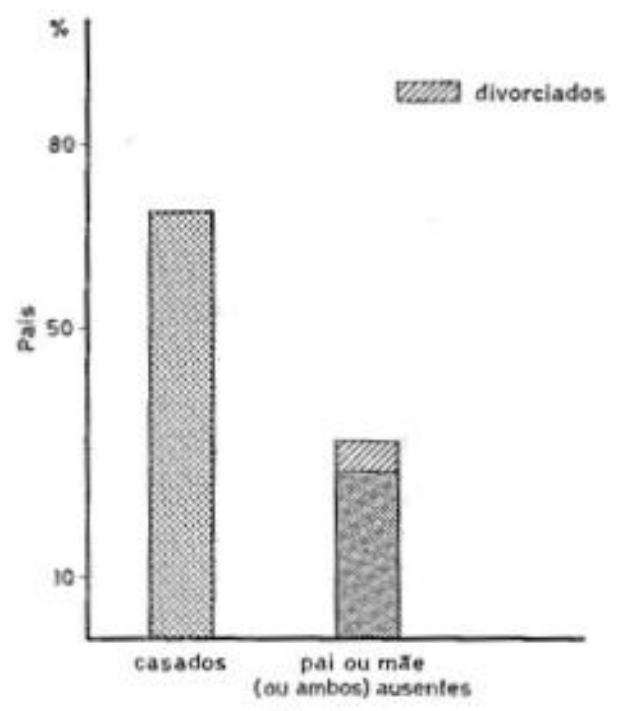

Fig. 4

\subsubsection{Fratria}

O estudo das fratrias, permite-nos verificar que para 106 respostas obtidas, as maiores proporções são de indivíduos que pertencem a familias numerosas.

Embora as familias no Norte do País sejam de um modo geral numerosas, os dados obtidos

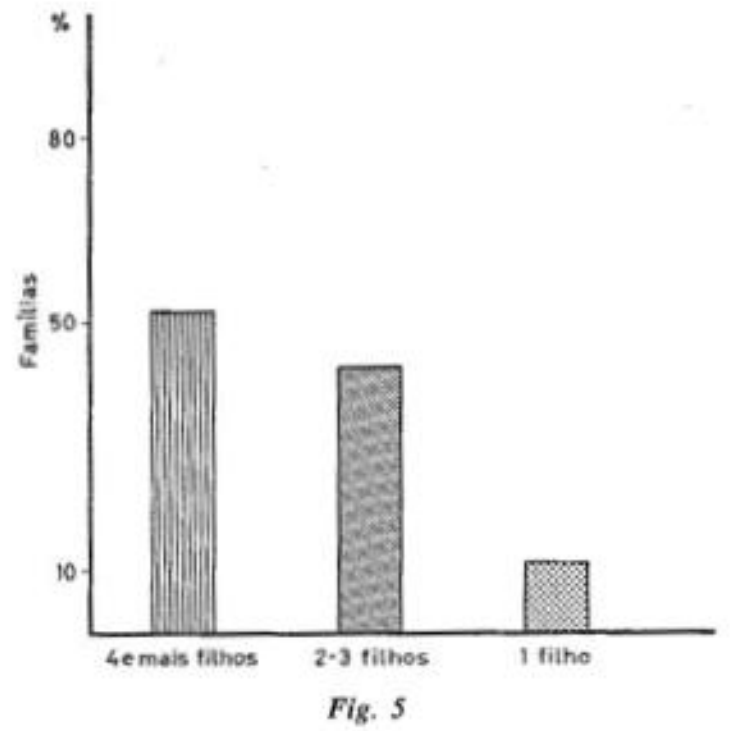

permitem-nos pensar que estamos perante um outro factor de risco.

\subsubsection{Estatuto sócio-profissional dos pais}

A análise do estatuto sócia-profissional dos pais só foi possível para 64 casos.

Para estes, pode-se constatar que, tal como acontecia com a nossa populaçắo utente, os pais se empregam fundamentalmente em actividades ligadas ao sector terciário (esta é praticamente o dobro da percentagem que se verifica ao nível do País: $34,3 \%$ ).

\section{QUADRO VIII}

REPARTICX̃O DOS PAIS ACTIVOS POR SECTOR DE ACTIVIDADE (EM \%)

\begin{tabular}{lccr}
\hline & Primario & Sectundírio & Tereilírio \\
\hline $\begin{array}{l}\text { Pais } \\
\text { Populaçăo activa }\end{array}$ & 3,1 & 28,1 & 68,8 \\
$\begin{array}{l}\text { em Portugal } \\
\text { em 1977 }\end{array}$ & 33,0 & 32,7 & 34,3 \\
\hline
\end{tabular}

ESTATUTO SOCIO-PROFISSIONAL (EM \%)

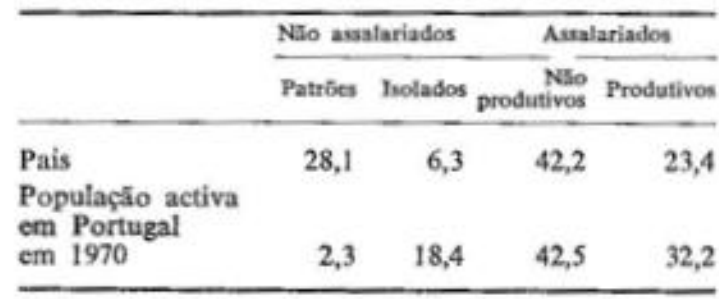


Quanto ao estatuto sócio-profissional, embora na sua maioria os pais sejam assalariados, mais de $1 / 4$ são patrões de indústria ou comércio.

Uma comparação com a distribuição da população activa no País põe em evidência o peso dos patrões e por contraste a baixa representatividade dos isolados (pequenos artesãos e pequenos comerciantes) nos pais, o que leva a supor que em geral o nível social das famílias dos utentes é bastante superior ao observado no País.

\subsection{Consumo de drogas}

Passemos agora à análise de alguns dados relativos ao consumo de drogas.

Verificámos que, para a nossa população (191 casos), a idade média do início do uso de drogas é os 16 anos e que a droga primeiro experimentada é na grande maioria dos casos $(84,6 \%)$ a liamba, seguida do haxixe e dos opiáceos, estes dois na mesma percentagem $(4,7 \%)$.

$$
\text { QUADRO IX }
$$

TIPO DE DROGA EXPERIMENTADA EM PRIMEIRO LUGAR

\begin{tabular}{lc}
\hline Droga de início & \% de indivíduos \\
\hline Liamba & 84,6 \\
Haxixe & 4,7 \\
Opiáceos & 4,7 \\
Anfetaminas & 2,7 \\
Ácidos & 1,3 \\
Outros & 2,0 \\
\hline
\end{tabular}

A maioria $(65,7 \%)$ dos nossos utentes consome habitualmente mais de quatro drogas, sendo a média dos consumos de perto de cinco drogas distintas e apenas $1,4 \%$ dos utentes disse usar apenas uma droga.

\section{QUADRO $\mathrm{X}$}

QUANTIDADE DE DROGAS DIFERENTES USADAS

\begin{tabular}{lc}
\hline N. ${ }^{\circ}$ de drogas usadas & $\%$ de indivíduos \\
\hline 1 & 1,4 \\
$2-3$ & 32,9 \\
$>4$ & 65,7 \\
\hline
\end{tabular}

O que nos permite dizer que a maioria dos jovens que vêm ao nosso serviço são politoxicómanos.

Podemos ainda constatar que a relação entre cada indivíduo e a droga por si preferencialmente usada conduz à seguinte hierarquia: 1. cannabis, $2 .^{\circ}$ narcóticos, $3 .^{\circ}$ estimulantes, $4 .^{\circ}$ depressores e $5 .^{\circ}$ alucinogénios.

Porém, esta hierarquia é alterada para os indivíduos com mais de 21 anos, em que as drogas mais frequentemente usadas são os narcóticos.

QUADRO XI

REPARTIÇÃO DOS INDIVIDUUOS SEGUNDO A DROGA PRINCIPALMENTE USADA E POR GRUPO ETARRIO

\begin{tabular}{lcrr}
\hline \multirow{2}{*}{ Droga + usada } & \multicolumn{3}{c}{ Idade } \\
\cline { 2 - 4 } & $<15$ & $15 / 21$ & $>21$ \\
\hline Cannabis & 90,9 & 51,9 & 27,4 \\
Narcóticos & & 27,4 & 54,9 \\
Estimulantes & & 13,2 & 11,8 \\
Depressores & 9,1 & 2,8 & 5,9 \\
Alucinogénios & & 4,7 & \\
\hline
\end{tabular}

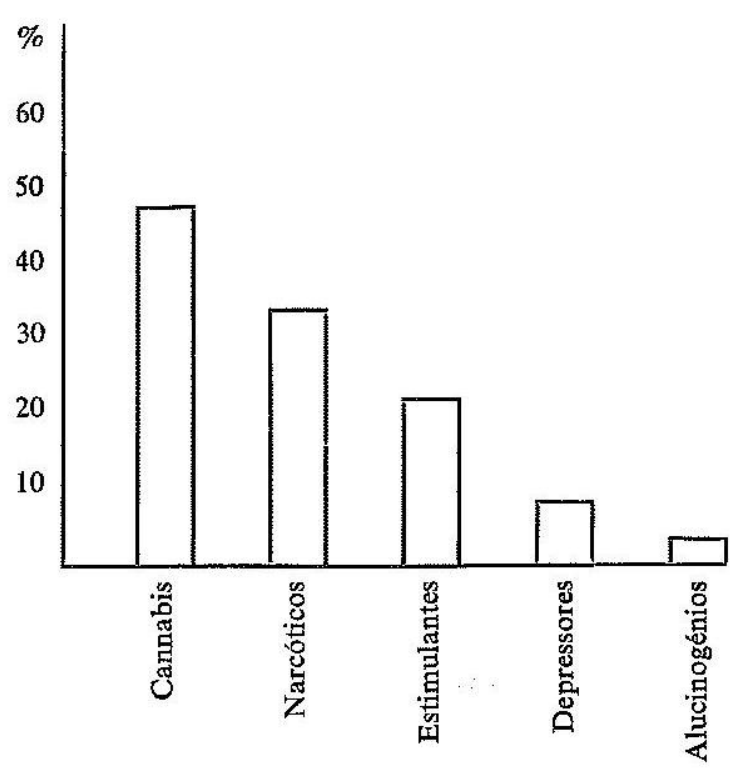

\subsection{Criminalidade}

Ir-nos-emos referir agora e para terminar, aos indivíduos que solicitaram o nosso apoio a partir dos estabelecimentos prisionais, encontrando-se ou a cumprir penas ou aguardando julgamento. 
Trata-se de uma população de 23 individuos, todos do sexo masculino, com uma média etária de 20,9 anos, ou seja, ligeiramente superior à encontrada para a outra populaçăo (20,4 anos).

Todos solteiros, à excepção de um. Mais de metade dos individuos que forneceram informações sobre a família, vêm de famílias dissociadas, ou seja, $43,8 \%$ săo órfãos de pai ou mãe ou não os conheceram, e em 6,3\% dos casos ambos os pais estão ausentes.

$78,6 \%$ dos casos de que dispúnhamos de informação, vêm de famílias muito numerosas, com 4 ou mais filhos.

Se compararmos estas últimas percentagens com as encontradas para a outra população anteriormente estudada, verificamos que aqui elas são mais elevadas, o que nos permite avançar, como hipótese, que estes são factores que, associados com outros, criam condições para a eclosão de comportamentos delinquentes.

$\mathrm{Na}$ altura da prisăo, $73,9 \%$ dos indivíduos encontravam-se desempregados ou não tinham ocupação, $21,7 \%$ trabalhavam e apenas $4,4 \%$ eram estudantes.

Quanto ao uso de drogas, trata-se de uma populaçăo de dependentes de narcóticos, à excepção de um (anfetaminas).

E, como implicaçăo criminal, encontrámos $69,6 \%$ de casos de furto, dos quais mais de metade săo assaltos a farmácias, $30,4 \%$ de uso ou tráfico de drogas e $4,3 \%$ de atentado aos costumes.

Estamos portanto em presença de uma população totalmente masculina, dependente de drogas duras, proveniente de famílias numerosas e muitas vezes de estrutura perturbada. Os delitos estão invariavelmente relacionados com a obtenção da droga, pois trata-se quase sempre da sua obtençăo directa ou dos meios financeiros para a obter.

Verificou-se portanto que as práticas delituais estão na maioria dos casos ligadas à necessidade de obtenção do produto, algo que se insere no processo da própria toxicomania e não como um acto delituoso em si, com uma intencionalidade própria.

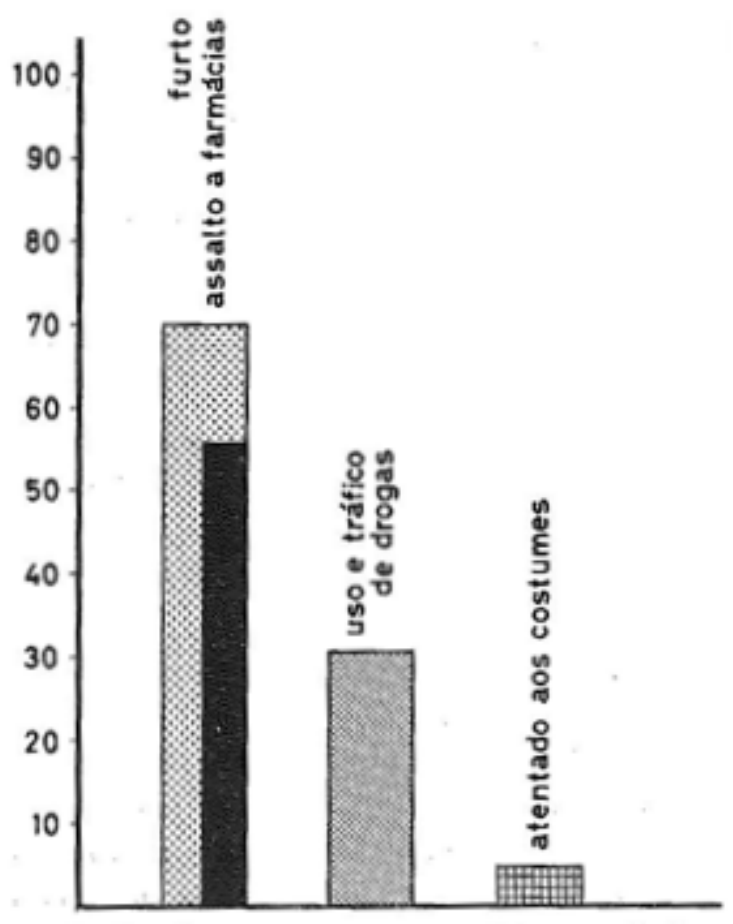

Fig.6 - Implicaçăo criminal dos toxicómanos detidos.

Este facto poderá eventualmente contrariar a opinião muito generalizada e quase sempre veiculada pelos mass-media de que o drogado é um indivíduo perigoso; ou, por outras palavras, que toxicomania e criminalidade sejam sinónimos.

\section{CONSIDERACOOES FINAIS}

Voltando agora e como conclusão ao objectivo que nos propusemos:

Que nos fica de paipável depois da frieza dos números? Qual o perfil deste drogado que nos procura em busca de ajuda? Já vimos que é ainda muito jovem, quase sempre solteiro e de meio urbano, não foi longe nos estudos, e, na maior parte das vezes, encontra-se desempregado ou sem ocupação.

Provém em maioria das classes médias. As famílias são numerosas e frequentemente dissociadas e quando não o são, as relaçōes interfamiliares estão geralmente perturbadas.

B um politoxicómano e quando se vê envolvido com a Justiça é ainda a droga que serve 
de pano de fundo, já que predominam os furtos para arranjar dinheiro e os assaltos a farmácias.

Mas que está para além dessa observação baseada na máquina de calcular? Como sentimos nós, na qualidade de psicoterapeutas, o dependente? Deixemos então os gráficos e olhemos para o jovem toxicómano à nossa frente. A ambivalência é constante, assim como os problemas familiares. Largar a droga é o fim desejado e apavorante, a liberdade frente a frente com o desconhecido.

A relação com o terapeuta é frustrante e dificilmente se desenvolve, feita de crises de desânimo e uma exigência sem limites, onde não há lugar para a elaboração dos conflitos. Se nos refugiarmos atrás de uma linguagem intelectualizada diremos que a personalidade é basicamente oral e o transfert existe, mas é precário. A terapia é difícil e não há lugar para uma posição de neutralidade, forçando o terapeuta a uma atitude activa. $\hat{E}$ preciso mergulhar com ele num mundo em que os fantasmas de omnipotência resistem ao princípio da realidade.

Mais do que uma terapia clássica é de um diálogo que se trata, sem certezas prévias da nossa parte. Pouco a pouco, nalguns casos, o real tornar-se-á menos ameaçador, o grupo menos indispensável e o jovem partirá, sem a muleta da droga, para não voltar.

Na maioria dos casos, contudo, a recaída é a regra, a frustração do terapeuta junta-se à do drogado e tudo recomeça. Rumo a um novo fracasso? É preciso admiti-lo para não falhar, porque existe sempre a possibilidade de recomeçar e com o drogado, mais do que com qualquer outro, é preciso saber esperar...

\section{RÉSUMÉ}

Les auteurs présentent dans cet article des données sociologiques et démographiques sur la population de toxicomanes qui demandent l'aide clinique du Centre d'Êtudes de la Profilaxie de la Drogue, au Porto.

La plupart des 191 cas observés est une population de jeunes gens, du sexe masculin, de 15 à 19 ans, appartenant aux classes sociales moyennes, sans formation scolaire assez differentée et sans emploi. Dans la plupart des cas, les relations familiales de ces jeunes présentent des anomalies.

Les auteurs presentent aussi des données statistiques sur les types de drogues consummées et montrent que dans la plupart des cas les clients du CEPD/Nort sont des polytoxicomanes. 